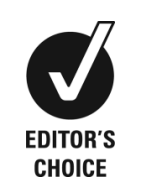

${ }^{1}$ Department of Health, RITM, Manila, Philippines

${ }^{2}$ University of the East-Ramon Magsaysay Memorial Medical Center, The Philippines ${ }^{3}$ Department of Health, Northern Samar, The Philippines

${ }^{4}$ Griffith Health Institute, Southport, Queensland, Australia

\section{Correspondence to} Professor Allen G Ross, a.ross@griffith.edu.au

Accepted 28 August 2015

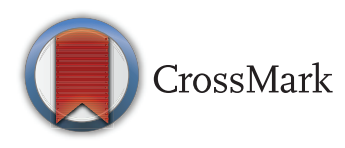

To cite: Vinluan $\mathrm{ML}$, Olveda RM, Ortanez CK, et al. BMJ Case Rep Published online: [please include Day Month Year] doi:10.1136/bcr-2015210084

\title{
Access to essential paediatric surgery in the developing world: a case of imperforate anus with rectovaginal and rectocutaneous fistulas left untreated
}

\author{
Marilyn L Vinluan, ${ }^{1}$ Remigio M Olveda, ${ }^{1}$ Clive K Ortanez, ${ }^{2}$ Modesto Abellera, ${ }^{2}$ \\ David U Olveda, ${ }^{2}$ Delia C Chy, ${ }^{3}$ Allen G Ross ${ }^{4}$
}

\section{SUMMARY}

Anorectal malformations consist of a wide spectrum of conditions which can affect both sexes and involve the distal anus and rectum as well as the urinary and genital tracts. Patients have the best chance of a good functional outcome if the condition is diagnosed early and efficient anatomic repair is promptly instituted. This report describes a rare case of imperforate anus associated with both rectovaginal and rectocutaneous fistulas in a 6-year-old Filipino girl. The case highlights shortcomings in the healthcare delivery system combined with socio-economic factors that contributed to the delay in both diagnosis and the institution of adequate treatment. Care and preventive measures that can be implemented in low-resource settings to reduce the impact of birth defects are also discussed.

\section{BACKGROUND}

A birth defect is defined as any abnormality affecting body structure or function that is present from birth. Congenital malformations of single systems, organs or limbs comprise the majority of birth defects with a prevalence of 36.5 per 1000 births. ${ }^{1}$ In the Philippines, a review of in-patient records from 1996 to 2000 at the Philippine General Hospital (PGH) listed congenital heart defects as the most common birth defect. This was followed by Hirschsprung disease, congenital atresia, and stenosis of anus without fistula. ${ }^{2}$

Anorectal malformations (ARM) include a wide spectrum of defects in the development of the lowest portion of the intestinal and urogenital tracts. Children with these malformations have no opening where the anus should be and are said to have an imperforate anus. ${ }^{3}$ However, the use of the latter term belies the complexity of this condition. Imperforate anus is an embryonic birth defect that results from incomplete formation of the hindgut, resulting in the absence or abnormal localisation of the anus around the eighth week of development. The rectum may end in a blind pouch or have openings to the urethra, bladder or vagina. ${ }^{4}$

Imperforate anus occurs in about 1 in 5000 live births; its aetiology remains unknown and is likely multifactorial. A genetic component is also possible because as early as the 1950 s, it was recognised that there was an increased risk (as much as $1 / 100$ ) for a sibling of a patient with ARM to be born with a malformation, compared with the incidence of about 1 in 5000 in the general population. ${ }^{5}$ There is a reported association between imperforate anus and prenatal thalidomide exposure, maternal diabetes mellitus and maternal age. ${ }^{4}$ Additionally, a recent systematic review and meta-analysis indicated that paternal smoking and maternal obesity were associated with increased risks for the development of ARM. ${ }^{6}$ Although no factors are known to prevent or reduce the risk for imperforate anus during pregnancy, a study conducted in China showed that daily maternal consumption of $400 \mu \mathrm{g}$ of folic acid before and during early pregnancy may reduce the risk for imperforate anus. ${ }^{4}$

Imperforate anus can be categorised based on sex specific classifications and the site of the associated fistula. In females, imperforate anus may be associated with fistulas to the perineum or vaginal vestibule and rarely to the vagina. ${ }^{7}$ The most common anomaly in females is a rectovestibular fistula. ${ }^{5}$ A fistula in the perineum or between the blind lower end of the rectum and urethra (bulbar or prostatic) or the bladder neck may occur with imperforate anus in males. Isolated imperforate anus can also occur in both sexes, while cloaca is a rare variant seen in females where the rectum, vagina and urethra open together in a common channel. $^{7}$

ARM has the unique aspect of having a higher association with congenital anomalies, with the reported range varying between $20 \%$ and $80 \%$. The most common associated anomalies reported worldwide were related to the urogenital system, the most frequent of which are renal agenesis, ectopic kidney, vesicoureteral reflux, hypospadias and undescended testes. Other systems such as the cardiovascular, gastrointestinal tract and nervous systems, can also be affected. ${ }^{8}$ Complex defects that are associated with other anomalies have a poor functional prognosis compared to minor defects without accompanying anomalies. ${ }^{5}$

The diagnosis of imperforate anus is usually made shortly after birth by routine physical examination. The majority of ARMs in girls can be diagnosed correctly on physical examination alone. An anal orifice visible on the perineum with a normal vagina and urethra is indicative of a perineal fistula. A rectovestibular fistula, on the other hand, occurs if the opening is in the posterior vestibule and 
outside the hymen. If only one orifice is seen between the labia, cloaca is highly likely. Rectovaginal fistulas may initially appear as imperforate anus with no fistula (normal-appearing vagina and urethra, but no visible anal orifice) but closer inspection will usually show the presence of an orifice in the posterior wall of the vagina or internal to the hymenal ring. ${ }^{9}$ Radiological evaluation of the newborn with an imperforate anus should include abdominal ultrasound to detect urological abnormalities (ie, distended vagina or hydrocolpos associated with persistent cloaca) and plain radiographs of the spine and sacrum to assess for anomalies. ${ }^{5}$

Sepsis, aspiration, abdominal distension, colonic perforation, respiratory distress, electrolyte imbalance and even death are complications that can arise from the delayed diagnostic and therapeutic management of ARM. ${ }^{10}$ The reported mortality rate of imperforate anus is between $1.4 \%$ and $30 \% .^{8}$ Undoubtedly, the importance of early diagnosis of imperforate anus cannot be over-emphasised. Immediate diagnosis will allow timely planning of subsequent management. Staged surgery, the most widely accepted approach for the management of ARM, consists of three operations: colostomy at birth, definitive operation after 2-3 months of age, and colostomy closure at the age of around 6 months. ${ }^{3}$ A posterior sagittal approach with anorectoplasty (PSARP) is the ideal definitive method to repair ARM. ${ }^{5}$ Regular follow-up in a bowel management treatment centre is needed in all these cases in order to achieve better continence. ${ }^{3}$ A combination of successful anatomical repair and appropriate programmes of bowel care can lead to socially acceptable continence in a majority of patients, especially those with an intact sacrum. ${ }^{11}$

We present an unusual case of imperforate anus presenting with rectovaginal fistula and concomitant rectocutaneous fistula. We also discuss the socio-economic factors that impeded the patient from getting access to early paediatric surgical care. Care and preventive measures that can be implemented in low and middle-income countries to reduce the impact of birth defects are also discussed.

\section{CASE PRESENTATION}

A 6-year-old Filipino female patient from a rural village in Northern Samar, the Philippines, presented with history of pasty-green to brownish stools per her vagina since birth. The patient was born full term to a then 36-year-old G4P3 (3-0-0-3) mother via cephalic spontaneous vaginal delivery. The mother had regular prenatal care check-ups at a rural health unit. The pregnancy was not complicated with gestational hypertension or gestational diabetes mellitus. The mother took iron supplements and denied tobacco, alcohol or illicit drug use during the pregnancy. The birthing process was attended by a midwife at home with no reported feto-maternal complications. The child was exclusively breastfed until 6 months of age; thereafter, formula milk and solid foods were gradually introduced. The patient's immunisations were complete and developmental milestones were appropriate for her age. Family history was unremarkable for congenital malformations.

The patient was apparently well until 1 month of age when her second eldest sibling noticed that her stools were coming out of her vagina. There were no other associated signs and symptoms, and so a medical consultation was not sought by the mother. When solid foods were introduced at 1 year of age, it was then that progressive abdominal enlargement was observed. Perineal cleansing had to be done every $30 \mathrm{~min}$ as greyish stools were frequently passed out from the vagina. There was no complaint of fever or vomiting.
The patient is the fourth child in a family of five children. Her 44-year-old father is a high school graduate and works as a carpenter and a motorcycle driver to provide for his family. His average income is about PHP 6000 (US\$135) a month. Her 42-year-old mother is a college graduate in nursing but is currently working as a utility worker in a local government office earning PHP 3000 (US\$67) a month. The parents were able to secure a loan of PHP 20000 (US\$450) from a local cooperative in order to take their daughter to Manila for surgical care.

The patient was brought to the PGH in Manila for medical consultation at the age of 2 . She was subsequently diagnosed with an imperforate anus and rectovaginal fistula and admitted to the charity surgical ward for operation. However, the child was taken off the operation list due to the higher priority given to emergency cases. After a month of waiting in the hospital, the parents decided to discharge their daughter and to re-admit her when a definite operation date could be confirmed. The family stayed at a relative's home in Manila for almost 8 months while waiting for the surgery resident to notify them about the availability of an operation. The father worked as a fish vendor in Manila to cover their daily expenses. Unfortunately, they were never contacted by the PGH surgery resident and decided to return home without care. Upon return, the patient started to verbally complain about abdominal pain associated with the abdominal enlargement. The child had a good appetite but was underweight for her age. Her social skills were also greatly affected as she refused to play with other children due to embarrassment about the malodorous discharge coming from her vagina. In 2012 the parents sought the help of a private donor (AGR) who was conducting clinical research in the community. Arrangements were made and the patient was subsequently admitted to the University of the East-Ramon Magsaysay Memorial Medical Center (UERMMC) for evaluation and further management.

Upon admission in late 2012, the patient had stable vital signs with a blood pressure of $90 / 60 \mathrm{~mm} \mathrm{Hg}$, pulse rate of $102 \mathrm{bpm}$, respiratory rate of $22 \mathrm{cycles} / \mathrm{min}$, and a core temperature of $36^{\circ}$ C. Pertinent physical findings included coarse crackles in the left lower lung field on auscultation. The measured abdominal circumference was $60 \mathrm{~cm}$, consistent with a globular and distended abdomen (figure 1A). Bowel sounds were normal, but there was a palpable $20 \times 21 \mathrm{~cm}$ firm, non-tender mass in the right upper quadrant. No direct or rebound tenderness was elicited on palpation. The rest of the physical examination was unremarkable.

Haematological tests revealed mild anaemia $(10.5 \mathrm{mg} / \mathrm{dL})$, normal white blood cell count with no left shift, and slight thrombocytosis. Serum sodium and potassium were within normal limits. Chest X-ray showed hazy opacities in the left parahilar region consistent with the diagnosis of pneumonia. Plain abdominal X-ray (figure 1B) demonstrated faecal stasis and focal areas of lucencies in the anterior right lateral and superior aspect of the abdomen which was indicativ of pneumoperitoneum. A working diagnosis of imperforate anus with rectovaginal fistula was made.

A subsequent referral to paediatric services for further evaluation and pre-operative care was carried out. Cefuroxime $250 \mathrm{mg}$ intravenous every $8 \mathrm{~h}$ was started to treat pneumonia. Nutritional supplements were initiated by gradually increasing the patient's caloric intake. On the 20th hospital day, the child underwent exploratory laparotomy with sigmoidectomy, appendectomy and colostomy. Intra-operative findings showed the sigmoid colon to be markedly distended with faeces and 

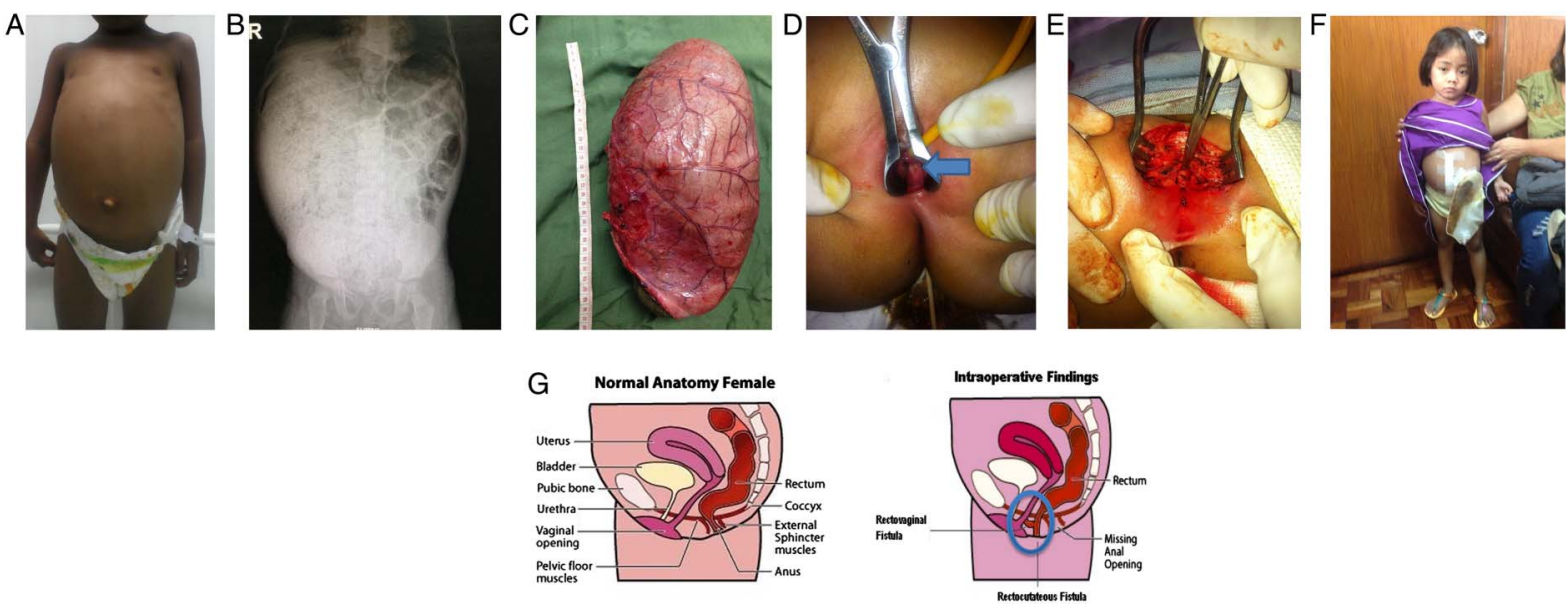

Figure 1 (A) Pre-operative photograph of the patient showing a markedly distended abdomen. (B) Plain abdominal X-ray of the patient demonstrating dilated bowel loops with faecal stasis and focal areas of lucencies suggestive of possible pneumoperitoneum. (C) Resected sigmoid colon showing a markedly distended bowel filled with faeces and severely compromised blood vessels. (D) Perineal examination revealing an opening corresponding to a rectovaginal fistula. (E) The thin blue arrow point to the distal rectum (internal opening), while the thicker blue arrow shows the external opening (perineum), indicating the rectocutaneous fistula. (F) The patient after undergoing sigmoidectomy and colostomy. (G) The intraoperative findings illustrated in a diagram to show the H-type fistula (encircled).

the blood vasculature severely compromised (figure 1C). Perineal examination showed the rectal orifice in the posterior wall of the vagina, consistent with the diagnosis of rectovaginal fistula (figure 1D). The patient's post-operative course was unremarkable and she was discharged on the sixth postoperative day.

With strict and explicit instructions on stoma care provided by the hospital staff to the mother, the family returned home to Northern Samar while waiting for the second stage of the operation. No peristomal skin infection was noted. The patient's nutritional status continued to improve and she has gained a tremendous amount of self-confidence, enabling her to play and interact with other children. She also currently attends school as a grade one pupil.

Approximately 9 months after the initial operation, the child was re-admitted at UERMMC for the second stage of surgery. She underwent PSARP with an unremarkable intra-operative and post-operative course. During the second operation a rectocutaneous fistula was also noted (figure 1E). The current plan is to allow the anorectal wound to heal followed by repeated and regular dilatation of the canal to prevent stricture of the neo-anus. The third stage of the surgery, which consists of the connection of the distal portion of the descending colon to the upper portion of the rectum and eventual closure of the colostomy, is scheduled to be completed in 2015. While waiting for the said procedure, the patient is expected to live a normal and functional life (figure 1F).

\section{GLOBAL HEALTH PROBLEM LIST}

- How should rare birth defects, such as anorectal malformations or imperforate anus, be managed in developing countries with limited healthcare resources?

- How does a parent's perception of the quality of healthcare services impact on their health seeking behaviour for their children?

- Should a national healthcare policy be created to ensure that all patients have access to essential surgical services as part of their basic human rights?

\section{GLOBAL HEALTH PROBLEM ANALYSIS}

Management and prevention of birth defects in low and middle-income countries

A report issued by the WHO in 1999 contended that governments in the developing countries should devote attention and resources to the control of genetic disorders and birth defects. Public health authorities should recognise the fact that these conditions are major causes of disease, disability and mortality in their countries. Programmes for the management and prevention of birth defects that can significantly reduce their burden in a cost-efficient manner should be initiated. ${ }^{12}$

In 2008, the March of Dimes Organization proposed costeffective interventions that can be carried out in low-income countries to reduce the impact of birth defects. ${ }^{13}$ Care and prevention can be implemented by expanding current maternal and child health programmes and developing medical genetic services in the secondary and tertiary tiers of health systems. The recommended measures are divided into two phases that can be tailored based on a country's financial state, health-care delivery status and specific health priorities. ${ }^{13}$

Phase one consists of improving the diagnosis, treatment and prevention of birth defects. Adequate training of primary-care providers on the screening and detection of birth defects should include learning to assess risk factors in a pregnant woman by taking a pertinent history. ${ }^{13}$ They should be also adept in conducting a thorough and complete newborn examination and identify recognisable dysmorphic features and patterns. Collating physical signs of birth defects that are visible externally is one way of rapidly diagnosing structural birth defects such as imperforate anus. ${ }^{13}$

The treatment of birth defects consists of improving human resources at the primary-care level and establishing surgical services for children with birth defects in allocated units in secondary and tertiary healthcare. ${ }^{13}$ The former heavily emphasises the role of primary-care practitioners, who should be able to aid in the follow-up of patients cared for in secondary and tertiary healthcare. In addition, training on genetic counselling, psychosocial support and basic rehabilitation for people with birth defects should be promoted. It is also recommended 
that individuals in the community are trained to assist in the rehabilitation process and lay support organisations are encouraged. ${ }^{13}$

Preventive measures include family planning, promotion of adequate and proper nutrition, food fortification and supplementation with essential micronutrients specifically iodine and folic acid, prevention of infections such as syphilis and rubella, and adequate control of maternal chronic illnesses such as diabetes mellitus and epilepsy. These steps should target both pregnant women and women of reproductive age. ${ }^{13}$

Depending on the country's needs and resources, phase two, which involves the employment of medical genetic services for risk identification and management, can be subsequently implemented. ${ }^{13}$ Prior to conception, the following are recommended: use of family history as a screening tool for risks for birth defects and cascade screening (carrier risk identification using family pedigrees and DNA analysis of identified individuals), ${ }^{13}$ antenatal screening procedures including assessment of Rhesus negativity, screening for Down syndrome and neural tube defects using maternal serum screen and ultrasound, and the use of fetal anomaly scanning to detect major malformations. ${ }^{13}$ Population carrier screening for common recessive disorders such as full blood count and electrophoresis for haemoglobin disorders can be carried out during the pre-conception and antenatal periods. Newborn screening for conditions such as congenital hypothyroidism and G6PD deficiency is also strongly advocated. ${ }^{13}$ These priority actions are intended to integrate seamlessly with a country's existing women's, maternal, newborn and child health programmes, and so new vertical programmes do not need to be developed. ${ }^{13}$

An effective programme of primary care can be expanded successfully (even in low-resource settings) to incorporate additional interventions such as genetic screening, into basic reproductive care. However, this can only be realised with government support and political commitment, and decisions regarding budget priorities should be guided with accurate data on the disease burden of birth defects and the cost-effectiveness of the proposed programmes. The successful thalassaemia prevention and treatment programme in Iran shows that a strong political will and accurate epidemiological data can result in cost-effective measures that reduce the impact of birth defects in a resource-poor setting. ${ }^{14}$

Unfortunately, most middle- and low-income countries currently lack the comprehensive health programmes necessary to reduce the impact of birth defects. ${ }^{1}$ In the Philippines, prenatal screening is practiced in a very limited way. The most widely used prenatal diagnostic procedure is prenatal ultrasonography, and first trimester ultrasound screening has been introduced in some urban medical centres. Non-invasive forms of prenatal diagnosis such as maternal serum screen are not routinely offered. ${ }^{15}$ Preventive programmes such as fortification of staple foods, that is, iron in rice, vitamin A in wheat flour, and iodised salt supplementation, do exist, but there is really no formal preconception care programme in the country. ${ }^{16}$ On the other hand, population-based screening conducted in the post-natal period, specifically newborn bloodspot screening (NBS), is more successful. NBS was integrated into the public health delivery systems in 2004. The national health insurance programme (Philhealth) initially covered 90\% funding of NBS but complete coverage was instituted in September 2011. ${ }^{16}$ In January 2014, NBS was expanded to include 22 more disorders such as haemoglobinopathies and additional metabolic disorders, in addition to the six previously screened diseases. ${ }^{17}$

\section{ANATOMY OF RECTAL ANOMALIES}

Our case illustrates an unusual type of imperforate anus associated with both rectovaginal and rectocutaneous fistulas. Worldwide, the most common anomaly in females is a rectovestibular fistula. ${ }^{5}$ A review of imperforate anus cases in countries such as Africa, ${ }^{18}{ }^{19}$ India $^{20}$ and Saudi Arabia ${ }^{7}$ revealed similar findings. A low frequency of rectovaginal fistulas was observed in Africa, with only $1.2 \%$ of 1401 patients diagnosed with the condition. ${ }^{19}$ A study conducted in Saudi Arabia also showed that rectovaginal fistulas were also unusual, occurring only in $2 \%$ of 53 females with imperforate anus. ${ }^{7}$ In the Philippines, a review of 189 imperforate anus cases showed that the most common type of associated fistula in females was of the anovestibular subtype. Cloacal (9\%) and rectovaginal fistulas (7\%) were actually more common than rectovestibular fistulas (1\%). ${ }^{21}$

A retrospective study of 619 cases of ARM in girls aimed to determine the true incidence of rectovaginal fistula. The study revealed that the incidence was only $1 \%$, which contrasts greatly with the literature published over the last 70 years. One explanation offered for this was that there is a much better understanding of the true anatomy of the different malformations today and that a cloaca is less commonly mistaken for a rectovaginal fistula. ${ }^{9}$ Differentiation between a cloaca and rectovaginal fistula is very important because its misdiagnosis has important therapeutic consequences. Obstructive uropathy and hydrocolpos commonly present with cloaca, and so diagnosing this as rectovaginal fistula may neglect the problem of obstructive uropathy. Another implication is that only the rectal anomaly would be repaired and the patient will have a persistent urogenital sinus. ${ }^{5}$ In our case, the demonstration of a rectal orifice internal to the hymenal ring established our diagnosis of a true rectovaginal fistula.

The presence of a concomitant rectocutaneous fistula also makes this case unique. A rectocutaneous fistula is an abnormal communication between the rectum and the peri-rectal skin. ${ }^{22}$ Our literature search showed only two reports with similar or closely related cases. The most recent report (1994) is of two newborn boys with imperforate anus associated with a recto-bulbar-cutaneous fistula. Both patients had a long fistulous tract originating from the rectal pouch and coursed deeply into the scrotum. In case 1 , the midportion of the fistula communicated with the bulbar urethra through a single small opening and exited in the scrotal raphe near the penoscrotal junction, while in case 2, it communicated over a longer segment and probably through several minute openings and exited in the anterior aspect of the penis also near the penoscrotal junction. ${ }^{23}$ The second report (1983) illustrated an imperforate anus with two fistulas, one ano-urethral and one penile urethro-cutaneous. ${ }^{24}$ Our case resembled more an $\mathrm{H}$-type fistula (figure $1 \mathrm{G}$ ) with the fistulous tract from the rectal pouch opening in the perineum, while a short fistula connects the rectal pouch to the distal portion of the vaginal canal and exits internal to the hymenal ring.

There have only been anecdotal reports of H-type fistula cases among paediatric surgeons in the Philippines. As far as we know, this case of a female patient with an imperforate anus associated with two fistulas occurs rarely.

\section{MANAGEMENT OF ARM}

Delays in both diagnosis and surgery were apparent in this case. Delayed diagnosis was defined as a diagnosis made after $48 \mathrm{~h}$ of life. Despite routine physical examination postpartum, one in five neonates born with imperforate anus had a delayed diagnosis. ${ }^{25}$ In a study conducted in Malawi, Africa, the median age at 
presentation was 24 days. The median age among boys was 3 days (range 1-24 days), while girls presented after a median age of 90 days (range 1-1185 days). ${ }^{19}$ A Philippine study also showed the same trend, with males presenting at a younger age (range 1-365 days) and females presenting at a later age (range 1 day-14 years). ${ }^{21}$ The wide range in the ages at consultation among the females can be due to the symptoms developing only in late childhood or early adolescence. In contrast, complications in males manifested earlier and their anomalies were more easily detected. ${ }^{21}$

In this case, the diagnosis of ARM was missed in the newborn period because the primary caregiver (midwife) was unable to perform a thorough physical examination. This is expected as local midwives are not routinely trained to conduct a proper examination and their lack of exposure to imperforate anus cases contributes to their lack of awareness and knowledge about the condition. Although the mother had a nursing background, she was also unable to detect the condition and it was only when obvious symptoms were manifested did she actually recognise the medical problem. However, the parents had the perception that the quality of health services in the capital city of Manila were far superior to those being offered in their own province. This led them to bypass their local primary-care services and go directly to a tertiary hospital in Manila.

The household's meagre income clearly delayed the family from accessing immediate surgical intervention for the patient. Education, especially that of women, is strongly related to many behaviours and choices favourable to good health, even after controlling for income. ${ }^{26}$ In this case, the lack of awareness of the parents led to further delays in seeking treatment. Once the parents were aware of their child's life-threatening complications, a sense of urgency prodded them to take a more proactive attitude in generating the needed out-of-pocket expenses so they could bring their child to PGH for treatment. In an ideal setting, the financial resources that they were able to access via a cooperative loan together with direct patient subsidies from their local elected politician's Priority Development Assistance Fund (PDAF) allocation, should have been enough to cover the cost of medicines, supplies and diagnostics while the child was in a public hospital. The devolution of healthcare to the local government unit, specifically its impact on the health referral system, also contributed to the delayed access to health services. In addition to a lack of a clearly defined referral system, a decline in the maintenance of infrastructure and under-financing of the operational costs of services also resulted in primary and secondary hospitals no longer being capable of providing referral services to health centres in their catchment areas. $^{27}$ Moreover, PhilHealth's (the national healthcare provider) No Balance Billing (NBB) policy, which provides that no other fees or expenses shall be charged to or be paid for by indigent patients above and beyond the packaged rates, only covers 11 surgical cases and excludes paediatric surgical procedures. ${ }^{28}$ Thus, indigent patients such as these must come up with the additional funds needed for surgery. Patients also need to cover their own travel costs and living expenses. This dilemma jeopardises the health of approximately half of the nation's 100 million people.

Unfortunately, negative perceptions (perhaps justified) about the substandard quality of care provided in rural and geographically poor provinces has led to severe congestion of patients in tertiary hospitals in the capital Manila. The hospitals have limited resources and manpower to cope with the sheer volume of patients admitted each day. The struggle of $\mathrm{PGH}$, which is the largest public hospital in the country, to handle this overwhelming number of patients has resulted in continuous reliance on state subsidies. In 2013, the approved national budget only allocated PHP 275 million (US\$6.25 million) for PGH's capital outlay. This amount is clearly below the PHP 990 million (US\$22.5 million) budget requested by PGH. ${ }^{29}$ This influx of patients into metro Manila clearly demonstrates an urgent need for a national policy to address the discrepancy in health services provided at the provincial level. The current referral system to Manila is not sustainable and is already impacting on the quality of care provided. Regrettably, many simply do not get the care they need.

\section{THE THREE DELAY FRAMEWORK}

The three delay framework explains the delay between onset of symptom and delivery of appropriate care in the context of maternal mortality. The first, second and third delays refer to delay in seeking, reaching and receiving care, respectively. ${ }^{30}$ This framework can also be used to describe the three types of delay in accessing surgical care. In the above case, the "first delay' occurred due to financial incapacity, low confidence in the health system and lack of awareness about the debilitating and fatal effects of the congenital malformation. The 'second delay' ensued due to geographical barriers and the high cost of travel and living expenses needed to reach the health facility. The 'third delay' arose when admission to the hospital did not guarantee receipt of care as the medical centre was already performing beyond the capacity of its personnel and resources.

The majority of birth defects are congenital malformations and many are amenable to paediatric surgery. ${ }^{1}$ Hence, a comprehensive national programme which aims to reduce the toll of birth defects should also incorporate a robust surgical system. This is timely as the Sustainable Development Goals (20152030) will replace the Millennium Development Goals (20002015). Universal health coverage by 2030 will also include surgery and the reporting of surgical indicators. ${ }^{31}$ The Lancet Commission on Global Surgery presented a national strategy plan addressing five major areas of surgical system development: infrastructure, workforce, service delivery, information management and financing. ${ }^{32}$ It is important for low and middle-income countries to gather epidemiological data, which should include both the prevalence of birth defects as well as assessment of the cost-effectiveness of interventions, in order to reduce the impact of birth defects in their countries. Using the template outlined by the Lancet commission, low and

Learning points

- Anorectal malformation or imperforate anus is a complex birth defect caused by incomplete formation of the hindgut, resulting in absent or abnormal localisation of the anus.

- Rectovestibular fistulas are the most common subtype; an imperforate anus with two concomitant fistulas is a rare occurrence.

- Early diagnosis and timely anatomic repair are vital for good clinical outcomes.

- Financial obstacles, negative perceptions about quality of care, congestion of tertiary government hospitals and inequity in access to health services contribute to delays in accessing essential surgical services in the developing world.

- National polices need to ensure that all patients have access to essential health services, including surgery, as part of their basic human rights. 
middle-income countries can now develop a national health plan incorporating access to surgical care. A strong and sustained political commitment and active involvement of the international community are also crucial for such a national policy to be effective.

Acknowledgements We thank the Australian National Health and Medical Research Council for providing financial support for our research.

Contributors All authors helped interview the parents and wrote the article.

Competing interests None declared.

Patient consent Obtained.

Provenance and peer review Not commissioned; externally peer reviewed.

\section{REFERENCES}

1 The March of Dimes global report on birth defects: The hidden toll of dying and disabled children. White Plains, New York: March of Dimes Birth Defects Foundation, 2006. http://www.marchofdimes.org/materials/global-report-on-birthdefects-the-hidden-toll-of-dying-and-disabled-children-full-report.pdf

2 Padilla CD, Cutiongco EM, Sia JM. Birth defects ascertainment in the Philippines. Southeast Asian J Trop Med Public Health 2003;34(Suppl 3):239-43.

3 Upadhyaya V, Gangopadhyay A, Srivastava P, et al. Evolution of management of anorectal malformation through the ages. Int J Surg 2007;17:1-17.

4 Myers MF, Li S, Correa-Villasenor A, et al. Folic acid supplementation and risk for imperforate anus in China. Am J Epidemiol 2001;154:1051-6.

5 Levitt MA, Peña A. Anorectal malformations. Orphanet J Rare Dis 2007;2:33.

6 Zwink N, Jenetzky E, Brenner H. Parental risk factors and anorectal malformations: systematic review and meta-analysis. Orphanet J Rare Dis 2011;6:25.

7 Kamal J, Rayes 0 , Kurdi M, et al. A collective review of cases with imperforate anus managed in a teaching hospital. Saudi J Health Sci 2012;1:122-5.

8 Mirza B, ljaz L, Saleem M, et al. Anorectal malformations in neonates. Afr J Paediatr Surg 2011;8:151-4.

9 Rosen NG, Hong AR, Soffer SZ, et al. Rectovaginal fistula: a common diagnostic error with significant consequences in girls with anorectal malformations. J Pediatr Surg 2002;37:961-5.

10 Tong W, Ludwig K. Neonatal colon perforation due to anorectal malformations: can it be avoided? World J Gastroenterol 2013;19:3915-17.

11 Rintala RJ, Pakarinen MP. Imperforate anus: long- and short-term outcome. Semin Pediatr Surg 2008;17:79-89.

12 World Health Organization. Services for the prevention and management of genetic disorders and birth defects in developing countries. The Hague, the Netherlands: World Health Organization Human Genetics Programme, 1999.
13 Controlling birth defects: Reducing the hidden toll of dying and disabled children in low-income countries. White Plains, New York: March of Dimes Birth Defects Foundation, 2008. http://www.marchofdimes.org/materials/partner-controlling-birthdefects-reducing-hidden-toll-of-dying-children-low-income-countries.pdf

14 Institute of Medicine Committee on Improving Birth OutcomesBale JR, Stoll BJ, Lucas AO, eds. Reducing birth defects: meeting the challenge in the developing world. Washington, DC: National Academies Press (US), 2003.

15 Cutiongco-de la Paz E. Prenatal diagnosis and its role in reproductive risk screening, prevention and treatment of genetic diseases: is the Philippines ready for it? Acta Med Philipp 2006;40:54-7.

16 Padilla CD, de la Paz EM. Genetic services and testing in the Philippines. J Community Genet 2013;4:399-411.

17 DOH approves expanded newborn screening program. http://www.pchrd.dost.gov. ph/index.php/news/r-d-updates/3137-doh-approves-expanded-newborn-screeningprogram

18 Beudeker N, Broadis E, Borgstein E, et al The hidden mortality of imperforate anus. Afr J Paediatr Surg 2013;10:302-6.

19 Moore SW, Alexander A, Sidler D, et al. The spectrum of anorectal malformations in Africa. Pediatr Surg Int 2008;24:677-83.

20 Bhargava P, Mahajan JK, Kumar A. Anorectal malformations in children. J Indian Assoc Pediatr Surg 2006;11:136-9.

21 Dy D, Almonte J. Imperforate anus: a review of 189 cases. Acta Medica Philippina 1989;25:25-7.

22 Erondu 0, Aniemeka J. Rare cases of rectocutaneous fistulas: basic radiological techniques and presentations. J Med Med Sci 2011;2:885-8.

23 Currarino G. Imperforate anus associated with a recto-bulbar-cutaneous fistula. J Pediatr Surg 1994;29:102-5.

24 Asano S, Kitatani H, Konuma K. A newborn with a covered anus complicated by two concomitant unique fistulas. Z Kinderchir 1983;38:258-61.

25 Turowski C, Dingemann J, Gillick J. Delayed diagnosis of imperforate anus: an unacceptable morbidity. Pediatr Surg Int 2010;26:1083-6.

26 Wagstaff A. Poverty and health sector inequalities. Bull World Health Organ 2002;80:97-105.

27 Grundy J, Healy V, Gorgolon L, et al. Overview of devolution of health services in the Philippines. Rural Remote Health 2003;3:220.

28 New PhilHealth Case Rates for Selected Medical Cases and Surgical Procedures and the No Balance Billing Policy. 2011.

29 Mendez C. P1-B allocation for UP capital outlay lauded. The Philippine Star. 2013.

30 Thaddeus S, Maine D. Too far to walk: maternal mortality in context. Soc Sci Med 1994;38:1091-110.

31 Watters D. Surgical intervention: how to improve access to surgical care in the developing world. 2015. http://www.policyforum.net/surgical-intervention/\#sthash. yTMxe64z.dpuf

32 Meara JG, Leather AJ, Hagander L, et al. Global surgery 2030: evidence and solutions for achieving health, welfare, and economic development. Surgery 2015;158:3-6.

Copyright 2015 BMJ Publishing Group. All rights reserved. For permission to reuse any of this content visit http://group.bmj.com/group/rights-licensing/permissions.

BMJ Case Report Fellows may re-use this article for personal use and teaching without any further permission.

Become a Fellow of BMJ Case Reports today and you can:

- Submit as many cases as you like

- Enjoy fast sympathetic peer review and rapid publication of accepted articles

- Access all the published articles

- Re-use any of the published material for personal use and teaching without further permission

For information on Institutional Fellowships contact consortiasales@bmjgroup.com

Visit casereports.bmj.com for more articles like this and to become a Fellow 